\title{
High yield synthesis of single-crystalline gold nanoplates using the metal ion-reducing bacteria
}

\author{
Takashi Ogi, Norizou Saitoh, Toshiyuki Nomura, Yasuhiro Konishi* \\ Department of Chemical Engineering, Osaka Prefecture University, 1-1 Gakuen-cho, Osaka 599-8531, Japan \\ Fax: 81-72-254-9911, e-mail: ogi@.chemeng.osakafu-u.ac.jp \\ * Department of Chemical Engineering, Osaka Prefecture University, 1-1 Gakuen-cho, Osaka 599-8531, Japan \\ Fax: 81-72-254-9297, e-mail: yasuhiro@chemeng.osakafu-u.ac.jp
}

Gold nanoplates were prepared in high yield at room temperature using the Fe(III)-reducing bacterium Shewanella algae. The cell extract, prepared by sonicating a suspension of $S$. algae cells, plays an important role in improving productivity of gold nanoplates. $S$. algae cell extract was capable of reducing aqueous $\mathrm{AuCl}_{4}{ }^{-}$ions into elemental gold within 60 min when $\mathrm{H}_{2}$ gas was provided as an electron donor. Gold nanoplates with an edge length of $100 \mathrm{~nm}$ appeared after 6 hours, and compact gold nanoplates with an edge length of 100-200 nm were obtained after 24 hours. The prepared nanoplates had diffraction spots characteristic of single-crystalline (111)-oriented gold nanocrystal. Using $S$. algae cell extract, the yield of gold nanoplates relative to the total nanoparticle population was $60 \%$, which was four times higher than that obtained with a suspension of resting cells. Following centrifugal ultrafiltration of the S. algae extract, only the fraction containing biomolecules greater than $50 \mathrm{kDa}$ successfully produced gold nanoplates.

Key words: microbial synthesis, gold nanoparticle, cell extract, eco-friendly process

\section{INTRODUCTION}

Noble metal nanoparticles have a wide range of applications such as in catalysis, optics and biosensing. The optoelectronic and physicochemical properties of nanoparticles are strongly correlated to both particle shape and size. The synthesis of gold nanoplates represents a fascinating and intellectually challenging problem due to their potential in cancer hyperthermia, as surface-enhanced Raman spectroscopy substrates, and as infrared radiation-absorbing optical coatings (1-2). Wet chemical methods have often been used to prepare gold nanoplates. Recent reports have detailed high yields of planar and triangular gold nanostructures produced with the crystal growth method and controlled by appropriate capping regents such as cetyltrimethylammonium bromide (CTAB) (3-5) and polyvinylpyrrolidone (PVP) (6-10). These chemical methods often require heating at elevated temperatures to complete the reduction of soluble $\mathrm{Au}$ ions. Furthermore, expensive chemicals are required, such as capping agents to control particle shape and a large amount of reducing agents. Therefore, finding feasible methods for producing gold nanoplates at room temperature without additives such as capping agents and reducing agents is advantageous for green chemistry.

Of recent interest is a low-cost and environmentally benign method for gold nanoplate synthesis using plant extracts to deposit gold metals by reducing gold ions in aqueous solution at room temperature. The Sastry group successfully prepared a gold nanoprism using plant extracts such as Cymbopogon flexuosus (lemongrass) (11) or Aloe vera (12). Excellent shape and selective formation of single crystalline triangular gold nanoparticles was observed. The Lee group developed a biological method to produce large quantities of gold nanoplates using a brown seaweed extract (13). Recently, our group reported on a microbial deposition of gold nanoplates using the metal-reducing bacterium Shewanella algae (14-15). This microbial method with metal-reducing bacteria was used to deposit metals by reducing the metal ions in an aqueous solution at room temperature and $\mathrm{pH}$ 3.2. This biological system provides an environmentally friendly and safe procedure for nanoparticle and nanoplate synthesis with low-energy consumption. However, the yield of gold nanoplates was relatively low and further detailed investigations are required to describe this process accurately and clearly.

In this study, we report for the first time on an eco-friendly method for the high yield synthesis of gold nanoplates using a cell extract prepared by sonicating a suspension of $S$. algae cells at room temperature without adjusting the $\mathrm{pH}$ of the solution. The effects of molecular weight, reaction time, and initial concentration of $\mathrm{Au}(\mathrm{III})$ ions on the particle morphology were investigated.

\section{EXPERIMENTAL SECTION}

Bacterial strain and growth conditions

S. algae ATCC51181 was obtained from the American Type Culture Collection (ATCC). Cells were cultured in ATCC medium 2 containing sodium lactate as an electron donor and $\mathrm{Fe}$ (III) citrate as an electron acceptor. For anaerobic conditions, $250 \mathrm{ml}$ of the liquid medium was added to a $500 \mathrm{ml}$ screw-cap flask and bubbled with $\mathrm{N}_{2}$ for $30 \mathrm{~min}$. The bacterial strain was grown anaerobically at $25^{\circ} \mathrm{C}$. The cells were harvested $24 \mathrm{~h}$ after batch inoculation, by centrifugation, re-suspension in distilled water under anaerobic gas, and re-pelleting by centrifugation. This procedure was repeated twice, and the washed cells were subsequently re-suspended in distilled water under anaerobic gas. The prepared $S$. algae suspension $(10 \mathrm{ml})$ was sonicated in a 
$50 \mathrm{ml}$ screw-cap flask in a bath sonicator (Ultrason Velvo Clear VS150H, $44 \mathrm{kHz}$ ) for $30 \mathrm{~min}$ at room temperature. The resulting $S$. algae cell extract was used for further experiments.

\section{Experimental procedure}

In a typical reduction experiment at $25^{\circ} \mathrm{C}, 5 \mathrm{ml}$ of the $S$. algae cell extract was added to $0.3 \mathrm{ml}$ of aqueous chloroauric acid $\left(\mathrm{HAuCl}_{4}\right)$ solution and the volume was increased to $15 \mathrm{ml}$ by adding an appropriate amount of distilled water. The gas phase was $\mathrm{H}_{2}-\mathrm{N}_{2}(80: 20$, v/v), with $\mathrm{H}_{2}$ gas provided as an electron donor. The cell concentration in the solution was $0.9-2.2 \times 10^{16}$ cells $/ \mathrm{m}^{3}$. The $\mathrm{pH}$ of the mixed solution was 2.8 , and no $\mathrm{pH}$ adjustment was required. The number of $S$. algae cells in the solution was counted in a Petroff-Hausser counting Chamber (Hausser Scientific, Horsham, PA, USA) with a microscope (BX51, Olympus, JAPAN). Fourier transform infrared spectroscopy (FTIR) measurement of the $S$. algae extract deposited on germanium cell were carried out on a Shimadzu FTIR-8700 in the diffuse reflectance mode operating at a resolution of $4 \mathrm{~cm}^{-1}$. The morphology and grain size of the biogenetic particles were observed by transmission electron microscopy (TEM) using JEOL model JEM-2100FX and JEM-2010. The biogenetic particles were also characterized by nano-beam electron diffraction (n-ED). Samples for TEM analysis were prepared on a carbon-coated copper TEM grid. To ascertain the characteristics of the biomolecules responsible for the formation of gold nanoplates, the $S$. algae cells extract was fractionated by centrifugal ultrafiltration using a $50 \mathrm{kDa}$ molecular weight cutoff membrane into two fractions: fraction 1 (biomolecules of MWs less than $50 \mathrm{kDa}$ ), and fraction 2 (biomolecules of MWs greater than $50 \mathrm{kDa}$ ).

\section{RESULTS AND DISCUSSION}

Figure 1(a) shows the TEM image of gold nanoplates obtained after $24 \mathrm{~h}$ with $S$. algae cell extract at $25{ }^{\circ} \mathrm{C}$ and $\mathrm{pH}$ 2.8. The concentration of $S$. algae cells was held constant at $2.2 \times 10^{16}$ cells $/ \mathrm{m}^{3}$.With $S$. algae cell extract, the biogenetic gold nanoparticles were deposited extracellularly and exhibited various morphologies, including a triangular, truncated triangular, and hexagonal shape. The prepared nanoplates had an edge length of 100-150 $\mathrm{nm}$ and tended to be larger than particles with other shapes (Figure 1(a)). The observed SAED pattern of the nanoplate showed diffraction spots characteristic of single-crystalline (111)-oriented gold nanocrystal (Figure 1b). Interestingly, the yield of gold nanoplates prepared using $S$. algae cell extract was larger than that prepared using $S$. algae cell suspension(Figure 1c). This higher yield of gold nanoplates suggests that the shape-control agent responsible for their production might be released from the bacterial cells into the aqueous solution of the cell extract. As a result, the shape-control agent can react with the generated gold nanoparticles more efficiently. The mechanism for gold nanoplate formation with lemongrass and Aloe vera extracts has been explained due to the presence of carbonyl groups which act as a shape-controlling agents adsorbing on selected facets of gold nuclei (11-13).
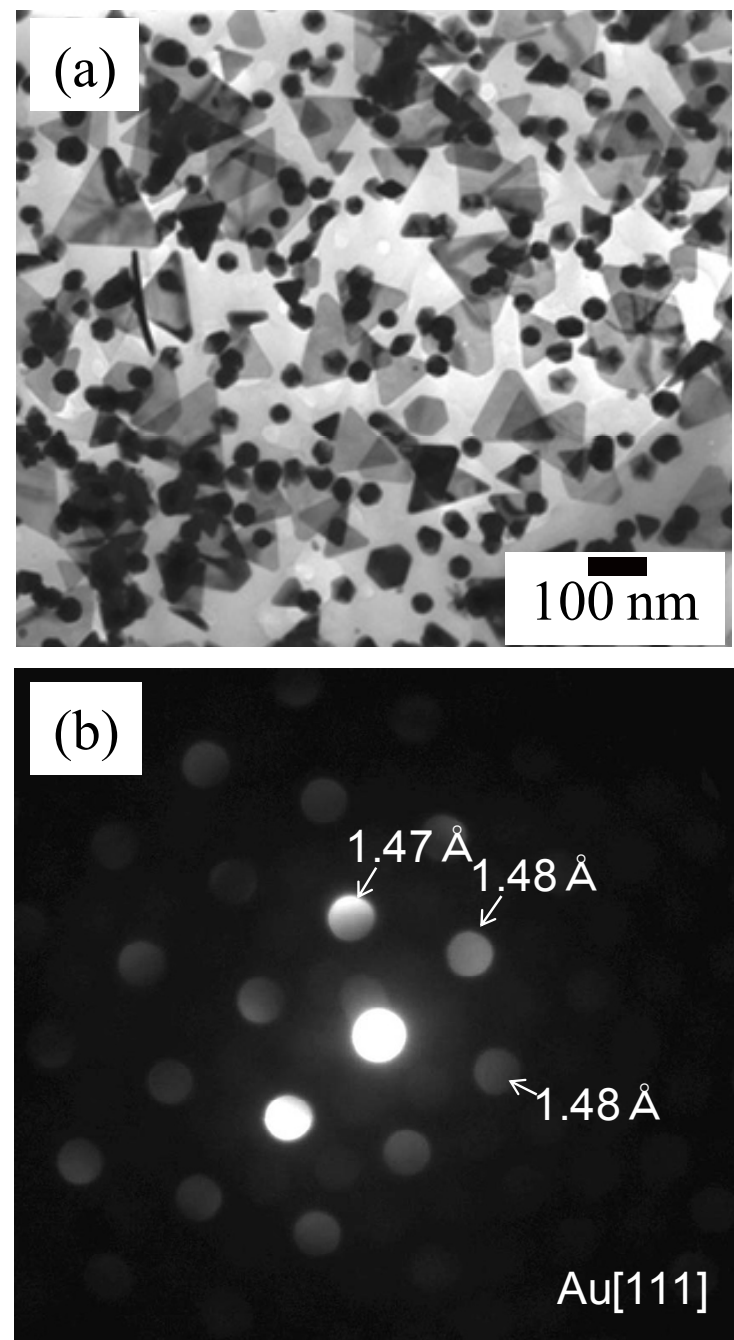

(c)

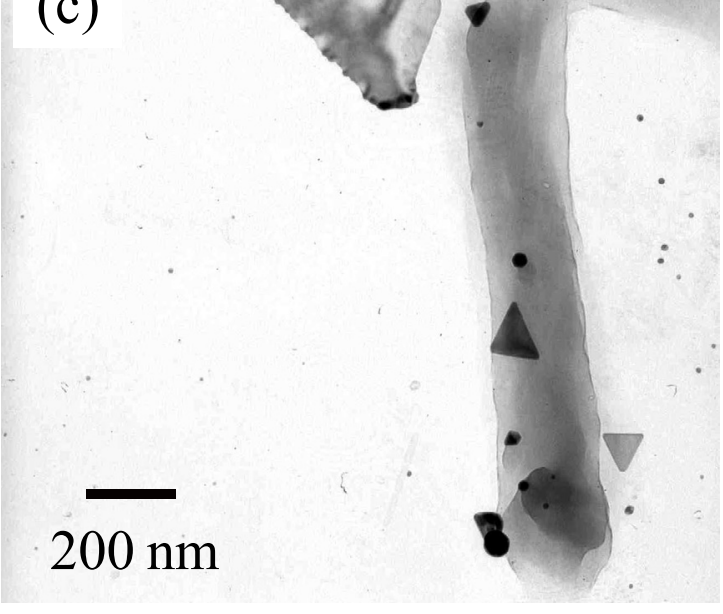

Figure 1. (a) TEM image of biogenetic Au nanoplates prepared using $S$. algae cell extract in the presence of $\mathrm{H}_{2}$ gas after $24 \mathrm{~h}$ at $25^{\circ} \mathrm{C}$ and $\mathrm{pH} 2.8$. (b) n-ED spots of the biogenetic particle shown in Figure 1(a). (c) TEM image of biogenetic Au nanoplates prepared by the resting cells of $S$. algae. 
To confirm the existence of such a shape-controlling agent in $S$. algae cell extract, FTIR analysis was performed (Figure 2). The observed FTIR spectrum of the $S$. algae cell extract showed a band at $1650 \mathrm{~cm}^{-1}$, assigned to the existence of a carbonyl functional group in ketones and aldehydes, which is responsible for the preparation of gold nanoplates.

To ascertain which biomolecules were responsible for the formation of gold nanoplates, the two fractions of $S$. algae cells extract obtained by ultracentrifugation (low-molecular-weight (less than $50 \mathrm{kDa}$ ) and high-molecular-weight (higher than $50 \mathrm{kDa}$ )) were individually reacted with $\mathrm{AuCl}_{4}{ }^{-}$ions in aqueous solution. Only fraction 1 was observed to cause formation of gold nanoplates (figure 3(a)). Large triangular and hexagonal gold nanoplates were seen in addition to smaller nanoparticles. On the other hand, nanoplates were not observed when fraction 2 was added to $1 \mathrm{~mol} / \mathrm{m}^{3} \mathrm{HAuCl}_{4}$ solution (Figure 3(b)). Thus, biomolecules with a molecular weight greater than 50 $\mathrm{kDa}$ play an important role in the formation of gold nanoplates.

\section{The effect of the reaction time on particle morphology}

Figure 4 shows the TEM images of gold nanoparticles produced after different reaction times with $S$. algae cell extract. The reaction time was found to be an important factor in controlling the morphology of biogenetic gold particles. In the early stages of reaction, well-dispersed spherical gold nanoparticles with a mean size $d_{\mathrm{p}}$ of 9.6 $\mathrm{nm}, \quad \sigma_{\mathrm{g}}$ of 1.34 were synthesized (Figure 4(a)). Agglomerations of nanoparticles were observed after $3 \mathrm{~h}$ (Figure 4(b)), and gold nanoplates $100 \mathrm{~nm}$ in size with a liquid fluid surface started to form after $6 \mathrm{~h}$. The TEM image indicates that the nanoparticles were generated on selected surfaces of the gold nanoplates (Figure 4(c)). Similar experimental results were also obtained when gold nanotriangles were prepared using lemongrass extract (11). After $12 \mathrm{~h}$ of reaction time, compact gold nanoplates with an edge length of 50-100 nm were observed, and the yield of gold nanoplates increased with time (Figure 4(d)). After one day with the cell extract, $60 \%$ of the total nanoparticle population was composed of gold nanoplates, and this was markedly higher than that obtained using resting cells.

The effect of the initial Au(III) concentration on particle morphology

Figure 5 shows the TEM images obtained after $24 \mathrm{~h}$ with different initial $\mathrm{Au}$ (III) ion concentrations (0.5-2.0 $\mathrm{mol} / \mathrm{m}^{3}$ ) at $25{ }^{\circ} \mathrm{C}$. The concentration of $S$. algae cells was held constant at $0.9-1.0 \times 10^{15}$ cells $/ \mathrm{m}^{3}$. At the initial $\mathrm{Au}(\mathrm{III})$ concentration of $0.5 \mathrm{~mol} / \mathrm{m}^{3}$, nanoplates with an edge length of 10-80 nm were produced along with small size of nanoparticles. When the $\mathrm{Au}(\mathrm{III})$ concentration was increased from 0.5 to $1 \mathrm{~mol} / \mathrm{m}^{3}$, the yield of the nanoplates increased (Fig. 5(b)). A further increase in $\mathrm{Au}(\mathrm{III})$ concentration resulted in the formation of larger nanoplates (Fig. 5(c)).

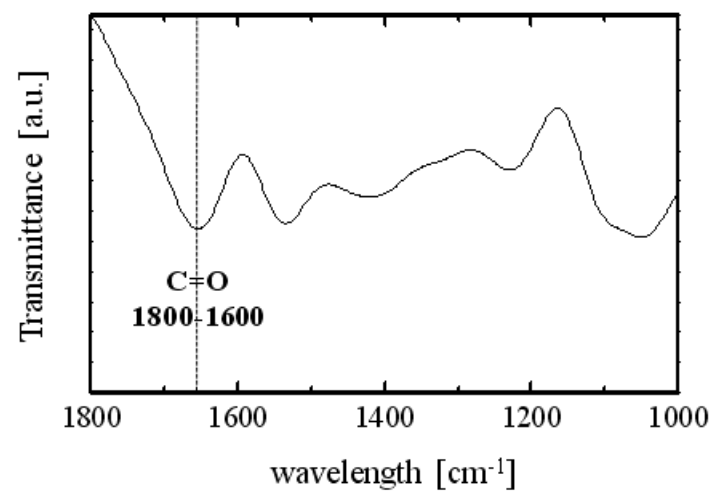

Figure 2. FTIR spectra of $S$. algae cell extract prepared by sonication of the $S$. algae suspension.
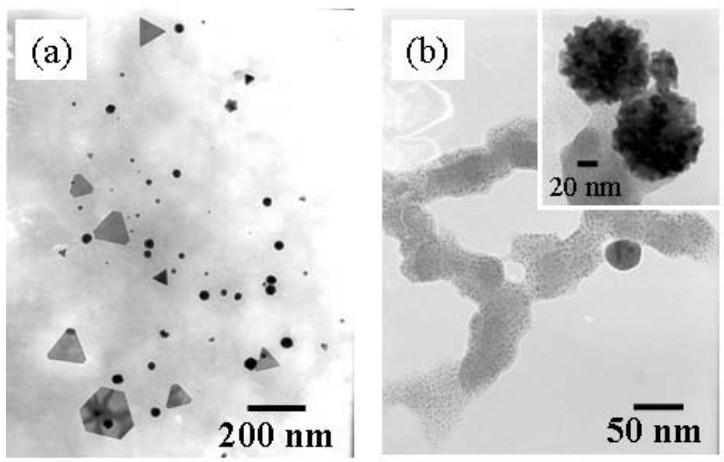

Figure 3. TEM images of biogenetic Au particles prepared in the presence of $\mathrm{H}_{2}$ gas after $24 \mathrm{~h}$ with either fraction 1 (a) or fraction 2 (b) of the $S$. algae cell extract.
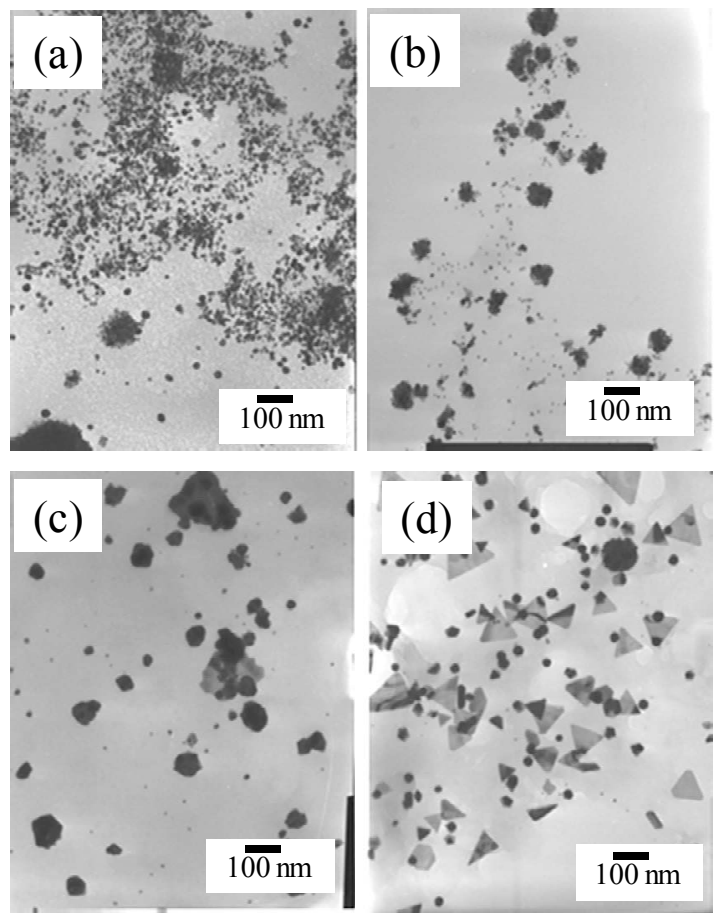

Figure 4. TEM images of Au nanoplates prepared after different reaction times with $S$. algae cell extract at 25 ${ }^{\circ} \mathrm{C}$ and $\mathrm{pH} 2.8$ in the presence of $\mathrm{H}_{2}$ gas: a) $1 \mathrm{~h}, \mathrm{~b}$ ) $3 \mathrm{~h}, \mathrm{c}$ ) $6 \mathrm{~h}$, and d) $12 \mathrm{~h}$. 


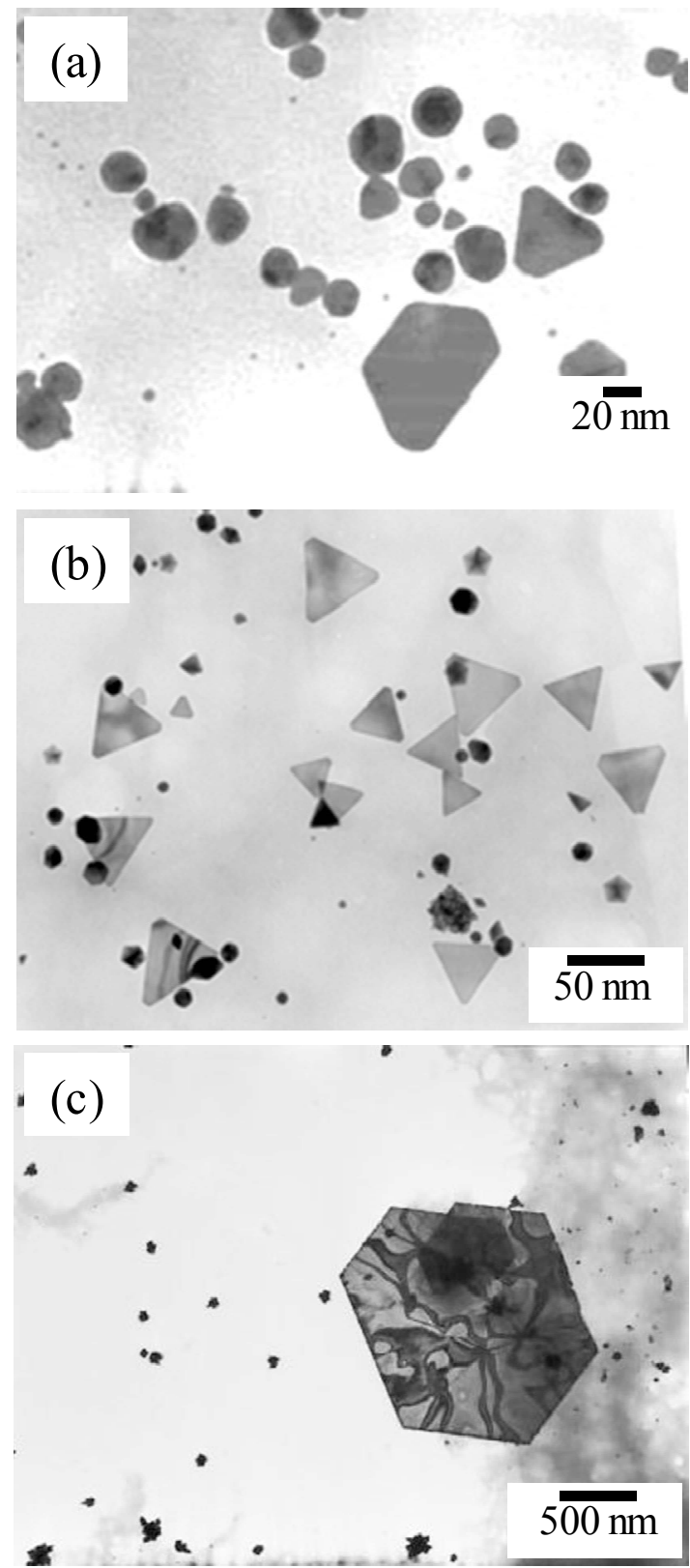

Figure 5. TEM images of Au nanoplates prepared using different initial $\mathrm{Au}(\mathrm{III})$ concentrations with $S$. algae cell extract at $25{ }^{\circ} \mathrm{C}$ and $\mathrm{pH} 2.8$ in the presence of $\mathrm{H}_{2}$ gas: a) $0.5 \mathrm{~mol} / \mathrm{m}^{3}$, b) $1.0 \mathrm{~mol} / \mathrm{m}^{3}$ and c) $2.0 \mathrm{~mol} / \mathrm{m}^{3}$.

\section{CONCLUSIONS}

Gold nanoplates were successfully produced at room temperature using $S$. algae cell extract without adjusting the $\mathrm{pH}$ of the solution. After $24 \mathrm{~h}$ of reaction time, gold nanoplates with an edge length of 100-200 nm were produced and the yield of gold nanoplates relative to the total number of particles formed was $60 \%$. Furthermore, this study revealed that the utilization of $S$. algae cell extract allowed production of higher yields of gold nanoplates compared to $S$. algae cell suspension. The bioreductive synthesis of gold nanoplates is potentially attractive as an environmentally friendly alternative to conventional methods.

\section{ACKNOWLEDGEMENTS}

This work was supported by a Grant-in-Aid for Scientific Research (B) (20360411) from the Ministry of Education, Science, Sports and Culture, Japan. We would like to thank Toray Research Center Inc., Shiga, Japan, for their assistance with TEM observations.

\section{REFERENCES}

[1] M.A. El-Sayed, Accounts Chem. Res., 34, 257-264 (2001).

[2] C. Burda, X.B. Chen, R. Narayanan, M.A. El-Sayed Chem. Rev., 105, 1025-1102 (2005).

[3] T.K. Sau, C.J. Murphy, J. Am. Chem. Soc., 126, 8648-8649 (2004).

[4] J.E. Millstone, S. Park, K.L. Shuford, L.D. Qin, G.C. Schatz, C.A. Mirkin, J. Am. Chem. Soc., 127, 5312-5313 (2005).

[5] H.C. Chu, C.H. Kuo, M.H. Huang, Inorg. Chem., 45, 808-813 (2006).

[6] Y.G. Sun, Y.N. Xia, Science, 298, 2176-2179 (2002).

[7] F. Kim, S. Connor, H. Song, T. Kuykendall, P.D. Yang, Angew. Chem-Int. Edit., 43, 3673-3677 (2004). [8] C.X. Kan, X.G. Zhu, G.H. Wang, J. Phys. Chem. B, 110, 4651-4656 (2006).

[9] J.H. Zhang, H.Y. Liu, Z.L. Wang, N.B. Ming, $A d v$. Funct. Mater., 17, 3295-3303 (2007).

[10] P. Jiang, J.J. Zhou, R. Li, Y. Gao, T.L. Sun, X.W. Zhao, Y.J. Xiang, S.S. Xie, J. Nanopart. Res. 8, 927-934 (2006).

[11] S.S. Shankar, A. Rai, B. Ankamwar, A. Singh, A. Ahmad, M. Sastry, Nat. Mater., 3, 482-488 (2004). [12] S.P. Chandran, M. Chaudhary, R. Pasricha, A. Ahmad, M. Sastry, Biotechnol. Prog., 22, 77-583 (2006).

[13] B. Liu, J. Xie, J.Y. Lee, Y.P. Ting, J.P. Chen, J. Phys. Chem. B., 109, 15256-15263 (2005).

[14] Y. Konishi, T. Tsukiyama, K. Ohno, N. Saitoh, T. Nomura, S. Nagamine, Hydrometallurgy, 81, 24-29 (2006).

[15] Y. Konishi, T. Tsukiyama, T. Tachimi, N. Saitoh, T. Nomura, S. Nagamine, Electrochim. Acta, 53, 186-192 (2007).

(Received March 23, 2009; Accepted September 28, 2009) 